Provided for non-commercial research and education use. Not for reproduction, distribution or commercial use.

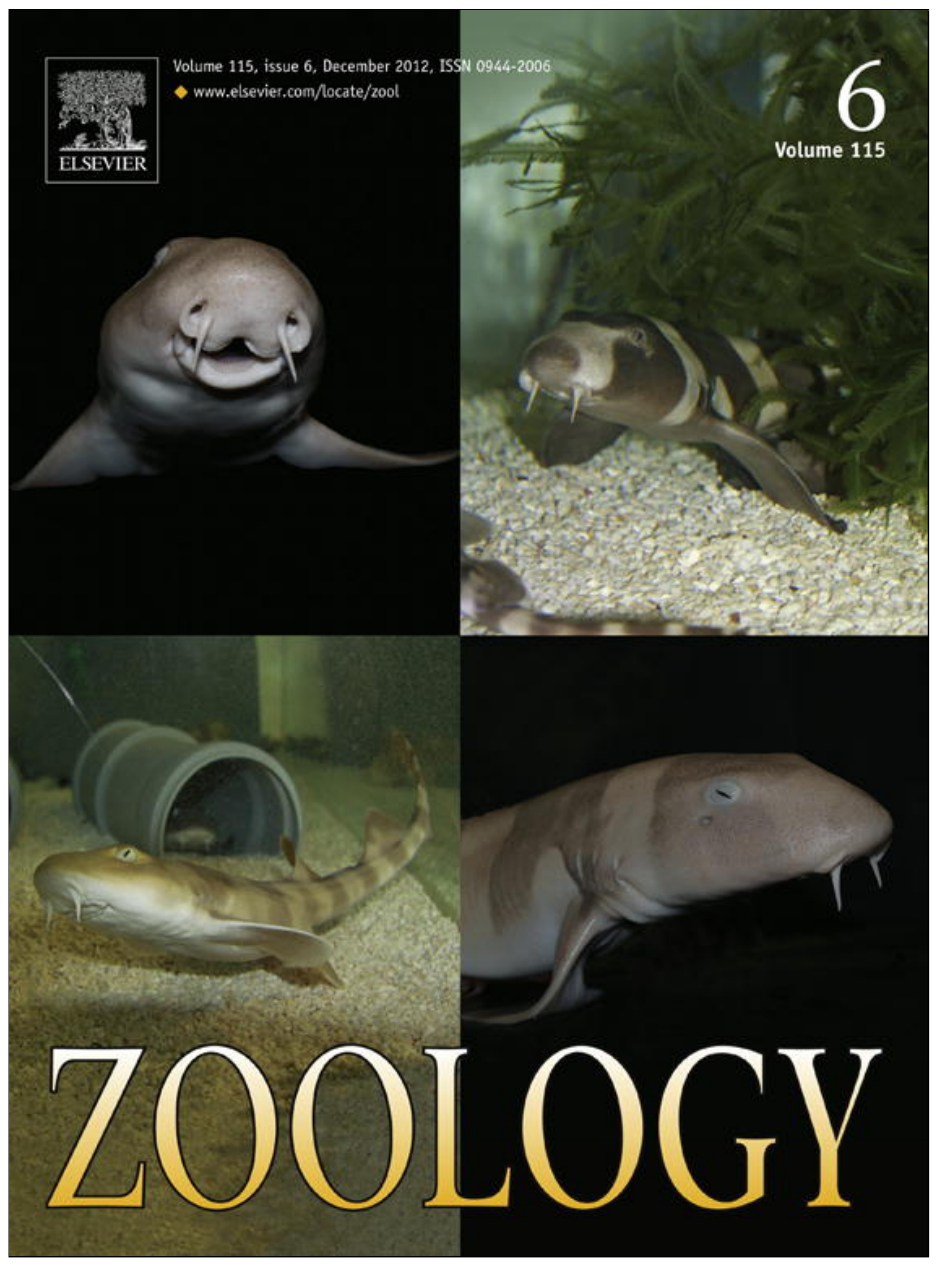

This article appeared in a journal published by Elsevier. The attached copy is furnished to the author for internal non-commercial research and education use, including for instruction at the authors institution and sharing with colleagues.

Other uses, including reproduction and distribution, or selling or licensing copies, or posting to personal, institutional or third party websites are prohibited.

In most cases authors are permitted to post their version of the article (e.g. in Word or Tex form) to their personal website or institutional repository. Authors requiring further information regarding Elsevier's archiving and manuscript policies are encouraged to visit:

http://www.elsevier.com/copyright 


\title{
Factors affecting variation in the reproductive investment of female treefrogs, Hyla intermedia
}

\author{
Giorgia Cadeddu*, Sergio Castellano \\ Dipartimento di Biologia Animale e dell'Uomo, Università di Torino, Via Accademia Albertina, 13, 10123 Torino, Italy
}

\section{A R T I C L E I N F O}

\section{Article history:}

Received 17 January 2012

Received in revised form 20 March 2012

Accepted 16 April 2012

\section{Keywords:}

Hyla intermedia

Egg size

Clutch size

Fecundity variation

Breeding season

\begin{abstract}
A B S T R A C T
In anurans, fecundity (clutch size) is the most important determinant of female reproductive success. We investigated three possible causes responsible for fecundity variation in female Italian treefrogs, Hyla intermedia, during four breeding seasons: (i) variation in morphological (body size and condition) and life-history (age) traits; (ii) variation in the tradeoff between the number and the size of eggs; (iii) seasonal effects and within-season differences in the timing of deposition. At the population level, we found no evidence for a tradeoff between the number and the size of eggs, because they both correlated positively with females' body size. Conversely, neither age nor post-spawning body condition showed any effect on female reproductive investment. Independent of body size, we found no evidence for variation in reproductive effort among different breeding seasons, but strong evidence for a decrease of clutch size and an increase of egg size with the advancing of a breeding season. To test for the functional significance of the observed temporal variation in allocation strategy, we carried out a rearing experiment in seminatural conditions on a random sample of ten clutches. The experiment showed a negative effect of clutch size and a positive effect of egg size on both tadpole growth and developmental rates, suggesting that reproductive investment, although constrained by body size, can be adjusted by females to the time of deposition to increase the chances of offspring survival.
\end{abstract}

(C) 2012 Elsevier GmbH. All rights reserved.

\section{Introduction}

In species without parental care, female fitness largely depends on fecundity and factors responsible for intra-specific variation in fecundity are expected to be under strong directional selection (Stearns, 1992; Roff, 2002). Variation in fecundity arises from the interaction of morpho-physiological constraints and life-history tradeoffs. Morpho-physiological constraints affect the amount of resources that females can acquire from the environment, store in their body, and invest in gamete production. Life-history tradeoffs represent the way females cope with these constraints in order to optimize their lifetime reproductive success (Stearns, 1992). The understanding of what causes intra-specific variation in female fecundity may give valuable insights into the selective forces responsible for the evolution of female life-history strategies.

In anurans, as well as in all animals with indeterminate growth, body size is one of the most important morphological constraints of fecundity, because of its allometric relationship with ovary mass (Wells, 2007). However, body size is also the expression of the tradeoff between growth, development and reproduction (Cadeddu et al., 2012). Females that invest large amounts of resources in

\footnotetext{
* Corresponding author. Tel.: +39011670 4559

E-mail address: giorgia.cadeddu@tiscali.it (G. Cadeddu).
}

growth would necessarily have fewer resources to invest in reproduction and they would attain large body size, usually, by delaying sexual maturity (Monnet and Cherry, 2002; Cadeddu et al., 2012). In these species, size-dependent differences in fecundity may thus arise from differences in age at maturity, that is, from different tradeoffs between the expected number of reproductive episodes and the reproductive success of each episode (Shine, 1988). Furthermore, age may directly affect variation in fecundity if the proportion of resources allocated to reproduction, rather than to growth and self-maintenance, increases with age (Gibbons and McCarthy, 1986; Berven, 1988).

Variation in fecundity, however, may be independent of life-history tradeoffs and be the consequence of among-female differences in the amount of available resources (Jörgensen, 1992). Some females may be genetically more efficient than others in converting external resources into metabolic energy or they may experience different environmental conditions, because of the spatial or seasonal heterogeneity of prey abundance (Kaplan, 1987; Madsen and Shine, 1999; Reading, 2004; Santos et al., 2005). Whatever the causes (genes, environment or gene-environment interaction), if resource variation is responsible for variation in fecundity, then we should expect, at the population level, patterns of co-variation largely inconsistent with those predicted by lifehistory tradeoffs, because females that have larger resources at their disposal may invest more both in growth and in reproduction 
than females with few resources (de Jong and van Noordwijk, 1992; Roff and Fairbairn, 2007).

Variation in fecundity, finally, may arise from differences in the allocation strategies of reproductive resources. In fact, provided that a female has a fixed amount of resources to invest in reproduction, the number of eggs she could produce depends on how she distributes this amount within the clutch, that is, on how she trades off egg number against egg size. Theoretical models predict that in a constant environment there should exist an optimal tradeoff between the size and the number of eggs (Smith and Fretwell, 1975) and that most of the variation in reproductive investment should be explained by variation in number rather than in size (Winkler and Wallin, 1987). These predictions, however, do not necessarily hold in species that live in variable and unpredictable environments (Dziminski et al., 2009). In anurans that breed in temporary freshwater environments, a tradeoff between the size and the number of eggs has often been observed (Kuramoto, 1978; Lips, 2001; Lüddecke, 2002). In these species, the amount of resources that offspring receive may have longterm effects on their body size: tadpoles from eggs with large yolk volumes hatch at a larger size (Tejedo and Reques, 1992; Loman, 2002), grow faster (Kaplan, 1985), run a lower predation risk (Travis et al., 1985; Banks and Beebee, 1988; Semlitsch and Gibbons, 1988; Richards and Bull, 1990) and metamorphosize at a larger size (Kaplan, 1985; Berven and Chadra, 1988) than tadpoles from smaller eggs. The beneficial effects of a large amount of offspring provisioning, however, depend on the quality of the environment (Crump, 1981), being usually more relevant in harsh than in benign environmental conditions. For this reason, variation in the quality of the offspring environment may favor both among-female variation in size-number tradeoffs and within-female variation in egg size (Dziminski et al., 2009).

Here, we investigate the causes of intra-specific variation in female fecundity in a species with indeterminate growth (thus, where there is a lifelong tradeoff between growth and reproduction) and without parental care (thus, where the only maternal investment is yolk provisioning). We use as a model the Italian treefrog, Hyla intermedia, an anuran showing a prolonged breeding season and an active female mate choice (Castellano et al., 2009). Specifically, this study has two main goals. First, we describe the pattern of intra- and inter-annual variation in clutch and egg size and how these components of reproductive investment covary with female age, body size and body condition. Second, we investigate the effect of egg size and number on tadpole growth and developmental rates to provide insights into the fitness consequences of variation in female reproductive investment.

\section{Materials and methods}

\subsection{Study species}

Formerly attributed to the European species Hyla arborea, the treefrog populations of the Italian Peninsula and Sicily were recently assigned to a separate species, $H$. intermedia, based on genetic studies (Nascetti et al., 1995). Just like the European treefrogs (Friedl and Klump, 2005), Italian treefrogs are prolonged breeders (sensu Wells, 1977) with a lek mating system: males congregate in large choruses, females visit the choruses and actively choose their partners on the basis of the quality of their advertisement calls (Castellano and Rosso, 2006, 2007; Rosso et al., 2006).

\subsection{Study area}

The study population bred in a dismissed paddy field inside the 'Parco della Valle del Ticino Piemontese' (PVTP), near Cameri
(Novara, Italy, $45^{\circ} 210^{\prime} \mathrm{N}, 8^{\circ} 660^{\prime} \mathrm{E} ; 178 \mathrm{~m}$ above sea level). The breeding site has been used by the PVTP authority in a long-term amphibian conservation project since 2001. A system of irrigation channels conveys water to the paddy field from the nearby Ticino river, thus permitting direct water-level control. In all four years of study (2006, 2007, 2009 and 2010), the paddy field was flooded in the second half of April and the water level was kept approximately constant (with a maximum depth of about $60 \mathrm{~cm}$ ) for the entire breeding season until autumn, when the breeding site was drained.

\subsection{Sampling and marking techniques}

Breeding activity started as soon as the site was flooded and terminated at the end of May. Every night during this period (from 9:00 p.m. to 1:00 a.m.), we moved along the shoreline and caught all pairing males and females. Pairs were carried to the laboratory and left to spawn overnight in separate plastic boxes $(25 \mathrm{~cm} \times 20 \mathrm{~cm} \times 10 \mathrm{~cm})$ filled with tap water. Paired males and females were anesthetized in a $0.2 \%$ solution of MS222 (Sandoz, Basel, Switzerland), weighed $( \pm 0.1 \mathrm{~g})$ with a digital scale (multifunction pocket scale MF-250; MTI Weight Systems, Inc., Kingstown, RI, USA) and their snout-vent length (SVL) was measured $( \pm 0.01 \mathrm{~mm})$ with a digital calliper (Mitutoyo CD-15C; Mitutoyo Inc., Kawasaki, Japan).

In 2006 and 2007, treefrogs were individually marked by implanting a fluorescent alphanumeric tag (VI Alpha Tags, size $1.0 \mathrm{~mm} \times 2.5 \mathrm{~mm}, 0.1 \mathrm{~mm}$ thick; Northwest Marine Technology Inc., Shaw Island, WA, USA) beneath the skin of the ventral side of the right hindlimb thigh (Castellano et al., 2009). In 2009 and 2010, females were toe-clipped by cutting out the last two phalanges of the fourth toe of their right hindlimb. These phalanges were preserved in a 70\% ethanol solution and successively used in skeletochronological analysis. Both males and females were released at the breeding site the morning after their capture and after full recovery from anesthesia.

\subsection{Clutch and egg size}

As soon as the pairs terminated spawning, we photographed the entire clutch with a digital camera (Canon PowerShot A75; Canon Inc., Tokyo, Japan). From three clusters of each clutch, we selected 15 eggs, which were photographed with a digital camera integrated on a stereomicroscope (Leica EZ4D; Leica Microsystems, Wetzlar, Germany) with $16 \times$ magnification. To prevent embryo mortality, clutches were left to develop under controlled laboratory conditions. Once hatching was completed, the tadpoles were released at the breeding site.

We used Image version 1.44 (National Institutes of Health, Bethesda, MD, USA) for the analysis of the digital pictures. On the entire-clutch pictures, we manually counted the total number of eggs laid by females, using the cell-counter function. After setting a scale of about 300 pixels $/ \mathrm{mm}$ in the single-egg pictures, we used the analyze-particle function to measure Feret diameters (i.e., the longest distance between any two points along the selection boundary), from which we estimated egg volumes.

\subsection{Age determination}

For skeletochronological analysis, we followed the procedure described by Cadeddu et al. (2012; see also Smirina, 1972). Preserved phalanges were cleaned, decalcified in $5 \%$ nitric acid for about $30 \mathrm{~min}$, and soaked in tap water overnight. Phalanx cross-sections $(12 \mu \mathrm{m})$ were obtained with a freezing microtome (Leica CM1850; Leica Microsystems, Wetzlar, Germany), stained with hematoxylin for $25 \mathrm{~min}$ and washed in water for $10 \mathrm{~min}$. 
In the mid-diaphyseal bone region the reabsorption process is limited (Gibbons and McCarthy, 1983), so we chose the sections with the narrowest medullar cavity derived from this area and mounted them on glass slides using Aqua-Mount (Thermo Scientific, Waltham, MA, USA). Two observers independently counted the number of lines of arrested growth in the sections under a light microscope and later compared results. Ambiguous sections were discounted. The outer margin of the sections was counted as an additional line of arrested growth, because specimens were collected just after emergence from hibernation (Rogers and Harvey, 1994).

\subsection{Rearing experiment}

In 2010, we selected 10 clutches, five laid on 24th April and five on 4th May. Clutches were left to develop under controlled laboratory conditions at a temperature of $19^{\circ} \mathrm{C}\left( \pm 1^{\circ} \mathrm{C}\right)$ until hatching was completed. From each clutch, we selected 40 tadpoles at stage 25 (Gosner, 1960), which were further split into two groups (20 tadpoles each). All groups were placed in separate plastic cages $(50 \mathrm{~cm} \times 30 \mathrm{~cm} \times 25 \mathrm{~cm})$ at a concentration of about 1 tadpole per 1.5 l. Cages were partially immersed into a water-storage cement basin ( $3 \mathrm{~m} \times 2 \mathrm{~m}, 2 \mathrm{~m}$ deep). On each side of the cages, inlets covered with mosquito netting prevented the entrance of large aquatic insects, but allowed for water exchange and influx of small planktonic organisms, which were the only source of food during the rearing experiment.

Once a week, we selected a random sample of 10 tadpoles from each cage. Each tadpole was placed on a Petri dish with a graph paper on the bottom and was photographed from above with a digital camera (Canon PowerShot A75), which was mounted on a photography stand at a constant distance from the tadpoles. After photographing, tadpoles were returned to their cages, which were randomly moved within the cement basin to prevent any position effect.

At the beginning of the experiment, due to uncontrolled predatory events, we observed a marked reduction in the number of tadpoles in five cages. Since larval density has a strong effect on growth rate, these high-mortality replicates were eliminated from the experiment.

\subsection{Maternal effects on larval development}

The rearing experiment allowed us to measure, for each clutch, the average developmental rate and the average growth rate of larvae. Developmental rate was the inverse of the time at metamorphosis (days elapsed from hatching to full tail resorption). To estimate average growth rate, we measured the tadpole SVL from the digital picture and calculated the mean larval body size for each clutch and week. To statistically control for differences in larval density among low-mortality cages, we estimated growth rate from a general linear model, which included clutch-mean larval body size as the dependent variable and clutch (random factor), number of survived tadpoles (covariate), age (days elapsed since hatching - covariate), and clutch-age interaction as independent factors. This analysis was carried out on the dataset of the first two months of larval development, when body size increased linearly with time. These growth rate estimates showed a strong correlation with clutch-mean SVLs at metamorphosis $\left(R^{2}=0.72 ; P=0.002\right)$.

\subsection{Statistical analyses}

To investigate the factors affecting female fecundity, we used a general linear model (GLM), in which clutch size (total number of eggs) was the dependent variable and (i) body size, (ii) body condition, (iii) deposition day, and (iv) year were the independent factors.
Body size (BS) was the first principal component calculated from the correlation matrix of log-transformed SVLs and post-spawning body weights (canonical loadings $=0.975$; percentage of variance explained $=94 \%$ ). Body condition $(B C)$ was the second principal component; it was positively correlated with body weight (canonical loadings $=0.26$ ) and negatively with body length (canonical loadings $=-0.26$ ). Females with high values of this component were considered in good body condition because they were heavier than expected from their body length. Deposition day was expressed in relative terms, as the number of days elapsed since the beginning of the breeding season. The year of study was entered as a random categorical factor to account for inter-annual differences in female reproductive success. This model was applied to the four-year sample. Since we measured age only in the 2010 breeding population, we could not use age as a covariate in the four-year sample. However, to test if age had any size-independent effects on clutch size, we used it in a multiple regression analysis with body size and condition.

To describe variation in egg size, we carried out a nested ANOVA, with year as a random factor, female identity as the first nested random factor, and cluster as the second nested random factor. Once it had been shown that egg size differed among females (see Section 3.3), we used a GLM to assess which factor could have been responsible for these differences. The model included female mean egg size as the dependent variable and five independent factors: body size, body condition, deposition day, year and clutch size. The latter variable was included to test for a tradeoff between the two components of female reproductive investment. This analysis was carried out on the 2009 and 2010 samples. To analyze the effects of age on egg size, we carried out a multiple regression analysis on the 2010 sample, with age, body size, body condition and clutch size as independent variables.

All statistical analyses were carried out using PASW vs. 18 (IBM Corp., Somers, NY, USA) and R 2.11.1 (The R Foundation for Statistical Computing, Vienna, Austria).

\section{Results}

\subsection{Female reproductive ecology}

During the four breeding seasons, we captured and measured 169 females: 23 in 2006, 89 in 2007, 10 in 2009 and 47 in 2010. Descriptive statistics are shown in Table 1 . SVL and body weight differed significantly among years $(P<0.001)$, as did BS $\left(F_{3,169}=13.0\right.$, $P<0.001)$ and $\mathrm{BC}\left(F_{3,169}=4.16, P=0.001\right)$. In 2010 , we analyzed the age of 37 out of 47 adult females which were on average $2.32 \pm 0.85$ years old (Fig. 1). A portion of females (16.2\%) had already reached sexual maturity at one year and $8.2 \%$ of females showed a maximum age of 4 years.

In the first two years of the study, 10 females (5 in 2006 and 5 in 2007) laid two clutches in the same breeding season, with a between-deposition mean delay of $15 \pm 1.2$ days in 2006 and $16 \pm 5.8$ days in 2007. Independent of the year, the first clutches were larger than the second ones (paired $t$-test: $t=3, \mathrm{df}=7$, $P=0.02)$. Controlling for $\mathrm{BS}$, we found that in both years $\left(F_{1,98}=3.08\right.$, $P=0.082$ ) double-clutch females produced a larger number of eggs than single-clutch females $\left(F_{3,169}=14.82, P<0.001\right)$. To avoid pseudo-replication, we omitted females with double depositions in the subsequent analyses.

\subsection{Clutch size}

Clutch size was a highly variable trait (Table 1 ), its coefficient of variation (CV) ranging from $31 \%$ (in 2009) to 84\% (in 2006). The GLM that best explained variation in clutch size included, as independent 
Table 1

Descriptive statistics of female body size (SVL and weight) and reproductive success (clutch size and egg size) in four breeding seasons of Hyla intermedia.

\begin{tabular}{|c|c|c|c|c|c|c|c|c|c|c|}
\hline & \multicolumn{10}{|c|}{ Year of study } \\
\hline & \multicolumn{2}{|c|}{2006} & \multicolumn{2}{|c|}{2007} & \multicolumn{2}{|c|}{2009} & \multicolumn{2}{|c|}{2010} & \multicolumn{2}{|c|}{ ANOVA } \\
\hline & $N$ & Mean \pm SD & $N$ & Mean \pm SD & $N$ & Mean \pm SD & $N$ & Mean \pm SD & $F$ & $P$ \\
\hline $\mathrm{SVL}(\mathrm{mm})$ & 22 & $36.08 \pm 3.47$ & 89 & $33.45 \pm 2.31$ & 10 & $34.43 \pm 3.15$ & 47 & $36.29 \pm 3.41$ & 12.17 & $<0.001$ \\
\hline Weight (g) & 23 & $3.37 \pm 1.03$ & 88 & $2.91 \pm 0.62$ & 10 & $3.22 \pm 0.83$ & 44 & $3.81 \pm 0.94$ & 13 & $<0.001$ \\
\hline Clutch size & 20 & $456 \pm 384$ & 82 & $440 \pm 284$ & 10 & $422 \pm 130$ & 44 & $616 \pm 327$ & 3.49 & 0.017 \\
\hline Egg size $\left(\mathrm{mm}^{3}\right)$ & & & & & 10 & $2.06 \pm 0.51$ & 46 & $1.92 \pm 0.25$ & 1.66 & 0.203 \\
\hline
\end{tabular}

factors, BS $(b=100.05$, se $=20.76, P<0.001)$ and deposition day $(b=-15.13$, se $=2.70, P<0.001)$ : clutch size increased with female body size (Fig. 2A) and decreased from the beginning to the end of the breeding season (Fig. 2B). In contrast, no significant differ-

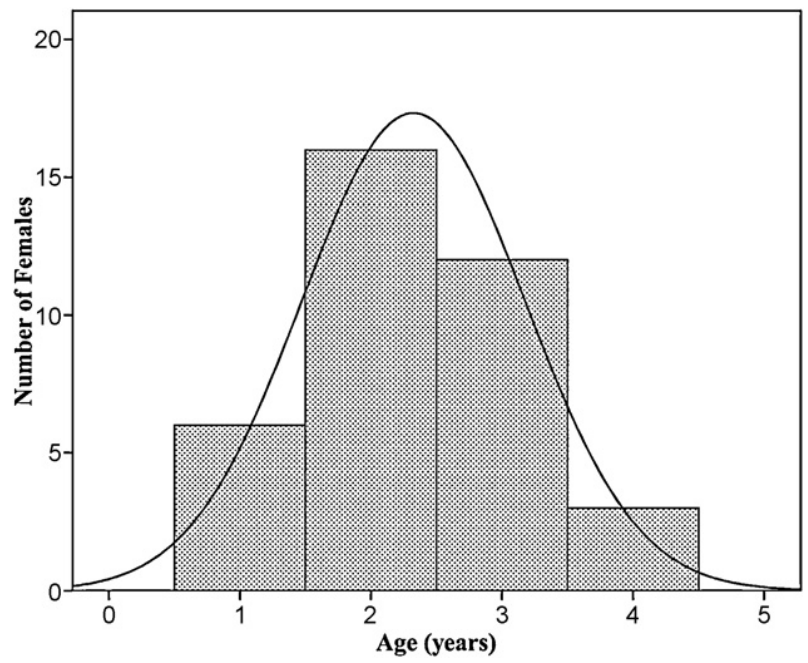

Fig. 1. Age-frequency distribution of female breeding tree-frogs (Hyla intermedia). As shown by the solid line, females were on average 2 years old, whereas some females (16.2\%) reached sexual maturity at one year.
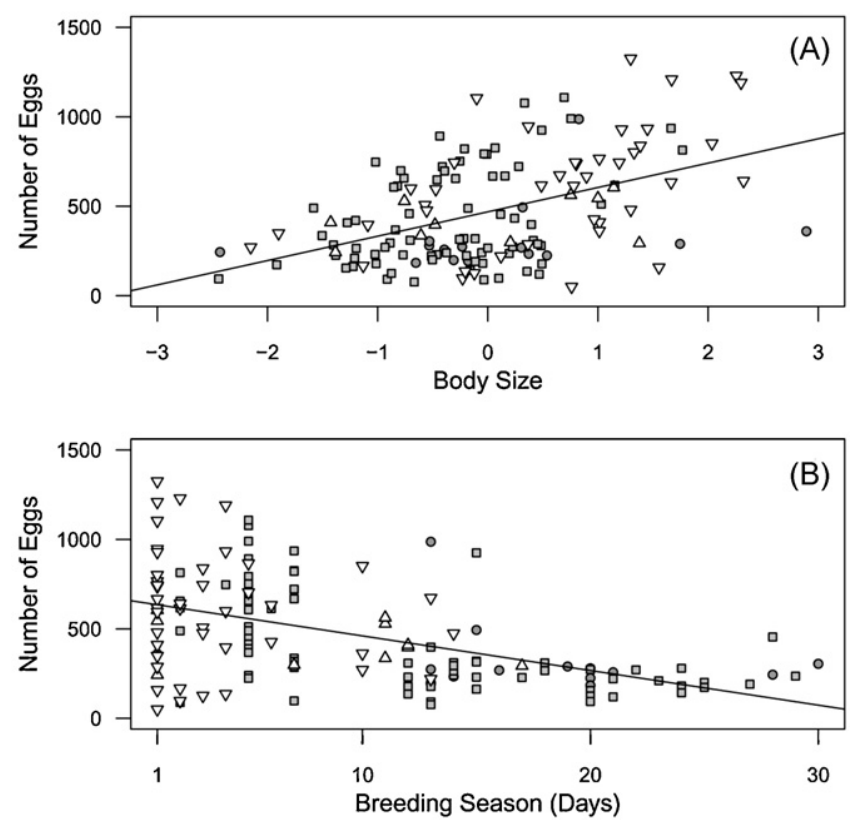

Fig. 2. The effect of (A) body size and (B) time of deposition on female clutch size in the 2006 (circles), 2007 (squares), 2009 (triangles) and 2010 (upside-down triangles) breeding seasons. Body size is the first principal component of the correlation matrix of SVL and body weight, whereas the time of deposition is defined in terms of the number of days since the start of the breeding season. ences were observed either among breeding seasons $\left(F_{3,136}=0.582\right.$, $P=0.628)$ or among females of different $\mathrm{BC}(b=11.36$, se $=20.89$, $P=0.587$ ). When we restricted the analysis to the 2010 sample to include age in the set of independent variables, the positive association between clutch size and BS was confirmed, but not between clutch size and age $(b=36.51$, se $=65.61, P=0.582)$.

\subsection{Egg size}

We measured the size (the spherical volume in $\mathrm{mm}^{3}$ ) of 800 eggs from 56 clutches: 148 eggs from 10 clutches in 2009, and 652 eggs from 46 clutches in 2010. The mean within-female CVs of egg size were $12.6 \%$ in 2009 and $12.7 \%$ in 2010 (range: 5.6-28.7\%). The mean among-female CVs were $25 \%$ in 2009 and $13 \%$ in 2010. The nested ANOVA showed significant differences among clutches $\left(F_{54,107}=15.4, P<0.001\right)$ and among clusters of the same clutch $\left(F_{108,636}=1.34, P=0.02\right)$. The GLM that best explained egg-size variation included BS and deposition day as independent factors. As observed for clutch size, large females tended to lay larger eggs than smaller females $(b=0.133$, se $=0.034, P<0.001)$ (Fig. 3A). Unlike clutch size, however, egg size tended to increase with the advancing of the breeding season $(b=0.025$, se $=0.008, P=0.003$ ) (Fig. 3B). Neither $\mathrm{BC}(b=0.06$, se $=0.05, P=0.196)$, nor year $\left(F_{1.45}=1.33, P=0.255\right)$ nor clutch size $\left(b=-7.59 \times 10^{-6}\right.$, se $\left.=1.42 \times 10^{-4}, P=0.958\right)$ showed any significant effect on egg size. A similar analysis, restricted to the
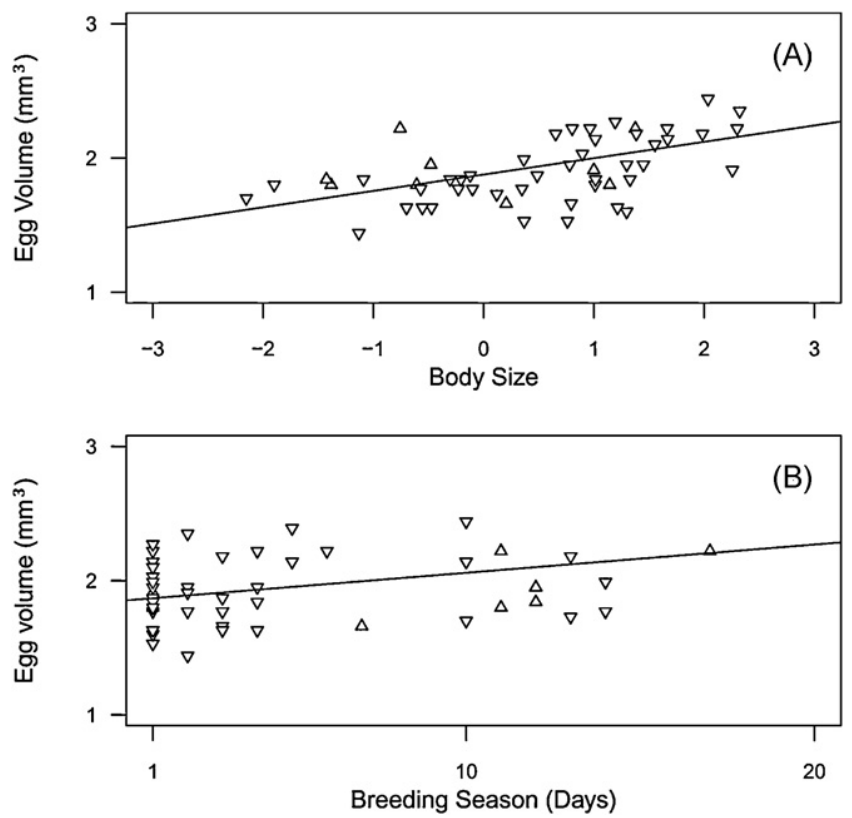

Fig. 3. The effect of (A) body size and (B) time of deposition on female egg size in the 2009 (triangles) and 2010 (upside-down triangles) breeding seasons. Body size is the first principal component of the correlation matrix of SVL and body weight, whereas the time of deposition is defined in terms of the number of days since the start of the breeding season. 
2010 sample, provided no evidence for an effect of age on egg size $(b=0.056$, se $=0.05, P=0.238)$.

\subsection{Maternal effects on larval development}

The GLM that best explained variation in larval growth rate included in the set of independent variables both the total number and the mean volume of eggs per clutch: the number of eggs negatively affected growth rate $\left(N=10 ; b=-6.3 \times 10^{-5}\right.$, se $=1.7 \times 10^{-5}$; $P=0.008$ ), whereas egg volume had a positive, but statistically nonsignificant, effect $(N=10 ; b=4.9 ; \mathrm{se}=2.4 ; P=0.076)$. Developmental rate correlated positively with growth rate $(N=10 ; R=0.896$; $P<0.001)$ and was affected negatively by the number of eggs in a clutch $\left(N=10 ; b=-3.5 \times 10^{-5} ; \mathrm{se}=1.2 \times 10^{-5} ; P=0.022\right)$, and positively by the mean egg size $(N=10 ; b=0.44$; se $=0.17 ; P=0.032)$.

\section{Discussion}

In anurans without parental care, female reproductive investment is mainly explained by the number and the size of eggs produced. In this long-term study, we investigated factors responsible for the observed variation in these two components of female reproductive effort. This study provides three main results. First, it shows that both the number and the size of eggs are positively correlated with females' body size, but not with their age nor with their post-spawning body condition. Second, there is no evidence for variation in reproductive effort between breeding seasons, but strong evidence for variation within breeding seasons: with the advancing of the breeding season, females tend to lay smaller clutches with larger eggs. Third, this study provides evidence for an opposite effect of clutch size and egg size on tadpole growth and developmental rates: independent of egg size, the larger the clutches the slower the tadpole growth; independent of clutch size, the larger the eggs the quicker the growth. In the light of these results, we subsequently discuss factors affecting variation in reproductive investment and their role in the evolution of optimal reproductive strategies of female treefrogs.

\subsection{Body size, age and reproductive investment}

In female Italian treefrogs, as well as in many other amphibian species (Wells, 2007), body size is positively associated with clutch size. Since in anurans with indeterminate growth body size often positively correlates with age (Halliday and Verrell, 1988), its effect on clutch size may be either direct or indirect (or both). It is direct if it depends on the allometric relationship that allows larger females to develop larger ovaries than smaller females (Castellano et al., 2004). It is indirect (or spurious) if older (and consequently larger) females invest proportionally more in egg production than younger (and consequently smaller) females. Since our results do not provide evidence for age-dependent differences in allocation strategies, they are consistent with the hypothesis that body size directly affects clutch size variation.

In many anurans, morphological constraints on fertility are viewed as one of the causes of sexual bimaturity (Monnet and Cherry, 2002; Kupfer, 2007). When the costs of female reproductive investment are high (Elmberg, 1991; Cox, 2006) and female reproductive success strongly depends on body size, young and hence small females are expected to postpone reproduction and to renounce immediate benefits in order to grow larger and to increase future fecundity (Roff, 2002). Consistent with this prediction, Cadeddu et al. (2012) found that female Sardinian treefrogs, Hyla sarda, reach sexual maturity not earlier than at two years of age and one year later than males. In our population, however, some females bred at one year of age and no between-sex differences in age structure were observed (Cadeddu, pers. obs.). This suggests that the costs and benefits of postponing reproduction differ between Italian and Sardinian treefrog females, possibly because of differences in survival probability.

Large females produce not only a greater number of eggs, but also eggs of larger size than smaller females. In contrast, we found no evidence for a direct effect of age on egg size. The positive association between body size and egg size is commonly observed among anurans (review in Kusano and Hayashi, 2002), whereas the relationship between age and egg size shows a less consistent pattern. In some species, egg size increases with age (Gibbons and McCarthy, 1986; Berven, 1988), whereas in others, no relationships are observed after controlling for body size variation (Tejedo, 1992; Kusano and Hayashi, 2002; the present study).

Overall, these results suggest that fast-growing females can invest more in reproduction than slow-growing females and, thus, that, at the population level, there is no evidence for a tradeoff between somatic growth and reproduction. Since the resources that a female can allocate to either growth or reproduction are limited, these tradeoffs necessarily exist at the individual level (Stearns, 1992; Roff, 2002) and they disappear at the population level because females differ in the amount of available resources (de Jong and van Noordwijk, 1992; Roff and Fairbairn, 2007): females with large resources can invest more both in the current reproduction and in growth, survival and future reproductive events (Lardner and Loman, 2003; Castellano et al., 2004).

\subsection{Intra- and inter-annual variation in reproductive investment}

Although body size is significantly correlated with clutch size and egg size, it explains a relatively small portion of their variance (17.5\% and $18.6 \%$, respectively). Since there is no evidence that a large reproductive investment reduces post-spawning body condition, the size- and age-independent variation in clutch and egg size is further evidence for the large among-female variation in available resources. Independent of their body size, high-quality females may afford larger investments than low-quality females because they are more efficient at converting external resources into internal metabolic energy (and ultimately into fitness).

Variation in reproductive investment, however, may also be a matter of quantity rather than efficiency and may depend on interand intra-annual variation in the amount of available resources. Inter-annual variation in climatic conditions, for example, may directly affect female feeding conditions and, indirectly, female reproductive investment. This is what is hypothesized to occur in Sardinian treefrogs, where large size-independent differences in female fecundity are observed among different breeding seasons (Cadeddu et al., 2012). Intra-annual variation may arise by differences in the timing of deposition. In species with prolonged breeding seasons, females can increase the amount of resources invested in eggs by delaying spawning. In this way, females can have more time to accumulate resources and to use them to complete the development of a larger complement of full-grown vitellogenic oocytes.

As concerns the pattern of inter-annual variation, we did observe among-season variation in female body size, but since we analyzed the age of females only in the 2010 breeding population, we do not know whether this variation was due to differences in growth rate or in population age structure (Friedl and Klump, 1997; Driscoll, 1999). Unlike in Sardinian treefrogs (Cadeddu et al., 2012), however, we found no differences in the linear relationships between body size and clutch size and, thus, no evidence for inter-annual, size-independent differences in female reproductive investment. Such a lack of differences may be due to constant climatic and ecological conditions during the study period or to the 
masking effect of the large intra-annual variation in reproductive investment that we did observe.

As concerns the pattern of intra-annual variation, our study shows an effect of the timing of deposition on female reproductive investment, but the temporal pattern observed was not consistent with the hypothesis that females delay reproduction to increase reproductive investment. According to this hypothesis, the reproductive investment is expected to increase with the advancing of the breeding season, whereas we observed that clutch size decreased and egg size increased. A decrease in clutch size was also observed in Bufo calamita (Tejedo, 1992) but, differently from our study, it was largely the side effect of smaller females spawning later in the season. Our results seem to support the alternative hypothesis that variation in the timing of deposition, once again, may depend on female energetic budget. Females in good feeding condition before hibernation might have been able to recruit a larger number of oocytes and complete vitellogenesis soon after the winter recovery, whereas females in poorer condition recruited a smaller complement of oocytes, which underwent a much longer vitellogenesis.

\subsection{Reproductive investment, timing of deposition and larval development}

Several lines of evidence show that female anurans benefit from breeding early (Matsushima and Kawata, 2005; Loman, 2009). Loman (2009) presents a number of plausible explanations: early-hatching tadpoles may suffer less intense intra- and interspecific competition (Loman, 2001; Matsushima and Kawata, 2005) and less severe predation risks than late-hatching tadpoles; by metamorphosing earlier, early-hatching tadpole may reach winter hibernation at a larger size (Altwegg and Reyer, 2003; Loman, 2009) and reach sexual maturity earlier (note that, in our population, some females bred at one year of age); finally, early-breeding females may be able to lay a second clutch in the same breeding season (Silverin and Andren, 1992; Denton and Beebee, 1996), thus increasing the number of offspring produced, as observed in our study.

Whether or not the decrease in clutch size with the advancing of the breeding season is the effect of energetic constraints, the increase in egg size may arise from a strategic choice. In fact, in some anurans, egg size is found to have long-term effects on larval growth and developmental rates (Kaplan, 1987; Berven and Chadra, 1988; Loman, 2002; Cherdantseva et al., 2007) and there is some evidence that females adjust offspring provisioning to maximize their fitness. For example, in the quacking frog, Crinia georgiana, Dziminski et al. (2009) found that egg size affects offspring fitness independent of maternal phenotype, but dependent on the quality of the developing environment. In this species, females are known to produce clutches with highly variable egg sizes, probably as a bet-hedging strategy evolved under unpredictable environments (Dziminski et al., 2009). Consistent with these results, we observed significant within-clutch (among-cluster) differences in egg size and our rearing experiment conducted on a random sample of ten clutches shows that clutch and egg size interact and act additively on tadpole growth and development: tadpoles from small clutches of large eggs tend to grow faster and to reach metamorphosis earlier than those from larger clutches of smaller eggs. These results suggest that females adjust their egg provisioning plastically: at the beginning of the breeding season, females invest more in the quantity than in the quality of their offspring, because tadpole density and the risk of pond desiccation are low; as the breeding season advances, maternal investment per single egg increases and the total number of eggs decreases.

\section{Conclusion}

In conclusion, we found that females vary a great deal in their reproductive investment and here we highlight two main components of this large variation. The first component is body-size dependent and we provide evidence that, rather than the expression of growth-reproduction life-history tradeoffs, it arises from among-female differences in the efficiency of converting external resources into internal metabolic energy. The second component is body-size independent and arises from the plastic allocation strategy that allows females to adjust their maternal investment to the time of deposition, in order to increase the chances of offspring survival.

\section{Acknowledgments}

Animal sampling was carried out under the authorization of the "Parco Della Valle del Ticino Piemontese" that also provided logistic support. V. Marconi, V. Zanollo, G. Berto, G. Bonadonna and E. Cannarsa helped in fieldwork, and E. Fioretti helped in laboratory analyses. Many thanks to P. Peretto and C. Giacoma for logistical support during skeletochronological analyses and to U. Sinsch and A. Kupfer for their constructive criticism on an early version of the manuscript.

\section{References}

Altwegg, R., Reyer, H.U., 2003. Patterns of natural selection on size at metamorphosis in water frogs. Evolution 57, 872-882.

Banks, B., Beebee, T.J.C., 1988. Reproductive success of natterjack toads Bufo calamita in two contrasting habitats. J. Anim. Ecol. 57, 475-492.

Berven, K.A., 1988. Factors affecting variation in reproductive traits within a population of wood frogs (Rana sylvatica). Copeia 1988, 605-615.

Berven, K.A., Chadra, B.G., 1988. The relationship among egg size, density and food level on larval development in the wood frog (Rana sylvatica). Oecologia 75, 67-72.

Cadeddu, G., Giacoma, C., Castellano, S., 2012. Sexual size dimorphism in the Tyrrhenian treefrog: a life-history perspective. J. Zool. (Lond.) 286, 285-292.

Castellano, S., Rosso, A., 2006. Variation in call temporal properties and female preferences in Hyla intermedia. Behaviour 143, 405-424.

Castellano, S., Rosso, A., 2007. Female preferences for multiple attributes in the acoustic signals of the Italian treefrog, Hyla intermedia. Behav. Ecol. Sociobiol. 61, 1293-1302.

Castellano, S., Cucco, M., Giacoma, C., 2004. Reproductive investment of female green toads (Bufo viridis). Copeia 2004, 659-664.

Castellano, S., Zanollo, V., Marconi, V., Berto, G., 2009. The mechanisms of sexual selection in a lek-breeding anuran, Hyla intermedia. Anim. Behav. 77, 213-224.

Cherdantseva, E.M., Cherdantsev, V.G., Lyapkov, S.M., 2007. The influence of egg size on the intensity and duration of Rana arvalis metamorph development in an experiment performed in a spawning water body. Zool. Zh. 86, 329-339.

Cox, R.M., 2006. A test of the reproductive cost hypothesis for sexual size dimorphism in Yarrow's spiny lizard Sceloporus jarrovii. J. Anim. Ecol. 75, 1361-1369.

Crump, M.L., 1981. Variation in propagule size as a function of environmental uncertainty for tree frogs. Am. Nat. 117, 724-737.

de Jong, G., van Noordwijk, A.J., 1992. Acquisition and allocation of resources: genetic (co)variates, selection, and life histories. Am. Nat. 139, 749-770.

Denton, J.S., Beebee, T.J.C., 1996. Double-clutching by natterjack toads Bufo calamita at a site in Southern England. Amphibia-Reptilia 17, 159-167.

Driscoll, D.A., 1999. Skeletochronological assessment of age structure and population stability for two threatened frog species. Aust. J. Ecol. 24, 182-189.

Dziminski, M.A., Vercoe, P.E., Roberts, J.D., 2009. Variable offspring provisioning and fitness: a direct test in the field. Funct. Ecol. 23, 164-171.

Elmberg, J., 1991. Ovarian cyclicity and fecundity in boreal common frogs Rana temporaria L. along a climatic gradient. Funct. Ecol. 5, 340-350.

Friedl, T.W.P., Klump, G.M., 1997. Some aspects of population biology in the European tree frog, Hyla arborea. Herpetologica 53, 321-330.

Friedl, T.W.P., Klump, G.M., 2005. Sexual selection in the lek-breeding European treefrog: body size, chorus attendance, random mating and good genes. Anim. Behav. 70, 1141-1154.

Gibbons, M.M., McCarthy, T.K., 1983. Age determination of frogs and toads (Amphibia, Anura) from north-western Europe. Zool. Scr. 12, 145-151.

Gibbons, M.M., McCarthy, T.K., 1986. The reproductive output of frogs Rana temporaria (L.) with particular reference to body size and age. J. Zool. (Lond.) 209, 579-593.

Gosner, K.L., 1960. A simplified table for staging anuran embryos and larvae with notes on identification. Herpetologica 16, 183-190.

Halliday, T.R., Verrell, P.A., 1988. Body size and age in amphibians and reptiles. J. Herpetol. 22, 253-265. 
Jörgensen, C.B., 1992. Growth and reproduction. In: Feder, M.E., Burggren, W.W. (Eds.), Environmental Physiology of the Amphibians. The University of Chicago Press, Chicago, pp. 439-466.

Kaplan, R.H., 1985. Maternal influences on offspring development in the California newt, Taricha torosa. Copeia 1985, 1028-1035.

Kaplan, R.H., 1987. Developmental plasticity and maternal effects of reproductive characteristics in the frog, Bombina orientalis. Oecologia 71, 273-279.

Kupfer, A., 2007. Sexual size dimorphism in amphibians: an overview. In: Fairbairn, D.J., Blanckenhorn, W.U., Székely, T. (Eds.), Sex, Size and Gender Roles: Evolutionary Studies of Sexual Size Dimorphism. Oxford University Press, Oxford pp. 50-59.

Kuramoto, M., 1978. Correlations of quantitative parameters of fecundity in amphibians. Evolution 32, 287-296.

Kusano, T., Hayashi, T, 2002. Female size-specific clutch parameters of two closely related stream breeding frogs, Rana sakuraii and $R$. tagoi tagoi: female size-independent and size-dependent egg sizes. Curr. Herpetol. 21, 75-86.

Lardner, B., Loman, J., 2003. Growth or reproduction? Resource allocation by female frogs Rana temporaria. Oecologia 137, 541-546.

Lips, K.R., 2001. Reproductive trade-offs and bet-hedging in Hyla calypsa, a neotropical treefrog. Oecologia 128, 509-518.

Loman, J., 2001. Intraspecific competition in tadpoles of Rana arvalis: does it matter in nature? A field experiment. Popul. Ecol. 43, 253-263.

Loman, J., 2002. Microevolution and maternal effects on tadpole Rana temporaria growth and development rate. J. Zool. (Lond.) 257, 93-99.

Loman, J., 2009. Primary and secondary phenology. Does it pay a frog to spawn early? J. Zool. (Lond.) 279, 64-70.

Lüddecke, H., 2002. Variation and trade-off in reproductive output of the Andean frog Hyla labialis. Oecologia 130, 403-410.

Madsen, T., Shine, R., 1999. The adjustment of reproductive threshold to prey abundance in a capital breeder. J. Anim. Ecol. 68, 571-580.

Matsushima, N., Kawata, M., 2005. The choice of oviposition site and the effects of density and oviposition timing on survivorship in Rana japonica. Ecol. Res. 20, 81-86.

Monnet, J.M., Cherry, M.I., 2002. Sexual size dimorphism in anurans. Proc. R. Soc. Lond. B 269, 2301-2307.

Nascetti, G., Lanza, B., Bullini, L., 1995. Genetic data support the specific status of the Italian treefrog (Amphibia: Anura: Hylidae). Amphibia-Reptilia 168, 215-227.
Reading, C.J., 2004. The influence of body condition and prey availability on female breeding success in the smooth snake (Coronella austriaca Laurenti). J. Zool. (Lond.) 264, 61-67.

Richards, S.J., Bull, C.M., 1990. Size-limited predation on tadpoles of three Australian frogs. Copeia 1990, 1041-1046.

Roff, D.A., 2002. Life History Evolution. Sinauer Associates, Sunderland.

Roff, D.A., Fairbairn, D.J., 2007. The evolution of trade-offs: where are we? J. Evol. Biol. 20, 433-447.

Rogers, K.L., Harvey, L., 1994. A skeletochronological assessment of fossil and recent Bufo cognatus from south-central Colorado. J. Herpetol. 28, 133-140.

Rosso, A., Castellano, S., Giacoma, C., 2006. Preferences for call spectral properties in Hyla intermedia. Ethology 112, 599-607.

Santos, X., Llorente, G.A., Feriche, M., Pleguezuelos, J.M., Casals, F., de Sostoa, A. 2005. Food availability induces geographic variation in reproductive timing of an aquatic oviparous snake (Natrix maura). Amphibia-Reptilia 26, 183-191.

Semlitsch, R.D., Gibbons, J.W., 1988. Fish predation in size-structured populations of treefrog tadpoles. Oecologia 75, 321-326.

Shine, R., 1988. The evolution of large body size in females: a critique of Darwin's 'fecundity advantage' model. Am. Nat. 131, 124-131.

Silverin, B., Andren, C., 1992. The ovarian cycle in the natterjack toad, Bufo calamita and its relation to breeding behaviour. Amphibia-Reptilia 13, 177-192.

Smirina, E.M., 1972. Annual layers in bones of Rana temporaria. Zool. Zh. 51, 1529-1534.

Smith, C.C., Fretwell, S.D., 1975. The optimal balance between size and number of offspring. Am. Nat. 108, 499-506.

Stearns, S.C., 1992. The Evolution of Life Histories. Oxford University Press, Oxford.

Tejedo, M., 1992. Effects of body size and timing of reproduction on reproductive success in female natterjack toads (Bufo calamita). J. Zool (Lond.) 228, 545-555.

Tejedo, M., Reques, R., 1992. Effects of egg size and density on metamorphic traits in tadpoles of the natterjack toad (Bufo calamita). J. Herpetol. 26, 146-152.

Travis, J., Keen, W.H., Juilianna, J., 1985. The role of relative body size in a predator-prey relationship between dragonfly naiads and larval anurans. Oikos $45,59-65$.

Wells, K.D., 1977. The social behaviour of anuran amphibians. Anim. Behav. 25, 666-693.

Wells, K.D., 2007. The Ecology and Behavior of Amphibians. The University of Chicago Press, Chicago.

Winkler, W., Wallin, K., 1987. Offspring size and number: a life history model linking effort per offspring and total effort. Am. Nat. 129, 708-720. 